\title{
La discapacidad como forma de diversidad humana en la narrativa española actual. EI significado de las imágenes de la discapacidad en Lectura fácil de Cristina Morales
}

\author{
Disability as a form of human diversity in the current \\ Spanish narrative. The meaning of disability images \\ in Lectura fácil by Cristina Morales
}

\author{
Justyna Ziarkowska \\ Uniwersytet Wrocławski \\ justyna.ziarkowska@uwr.edu.pl
}

\begin{abstract}
The representation of the disability in the recent Spanish narrative raises several questions: by the role and place that the excluded occupy in the fictitious worlds, by the point of view and the tonality in which they are represented, by the reaction of the other participants of fiction. In the recent novel by Cristina Morales titled "Lectura fácil", four protagonists are presented with intellectual disability. For his condition the metaphor of slavery is used, but it is not an internal oppression, but external and institutional one. The social system is much more oppressive and violent than the experience of the disease itself. They radicalize and oppose the therapeutic and normalizing attempts of society and thus question the dominant culture. The presentation of the disability made by Morales lacks the perspective of superiority, but also cedes from a different emotional perspective compared to the portraits of normative characters.
\end{abstract}

Keywords: disability, institutional oppression, Cristina Morales

La consciente fealdad de los personajes representados -los cuerpos deformados y enfermos o las mentes discapacitadas demostrando la fragilidad de la identidad humana- constituye un dato que se repite frecuentemente en la literatura y las obra 
de arte españolas. Es una forma con la que la cultura hispánica está domesticando la discapacidad. Lo advirtió por ejemplo Wolfgang Kayser confesando en el prólogo a su conocido libro monográfico sobre Lo grotesco que: "Hace quince años, cuando recorría por primera vez el Museo de Prado, se despertó mi curiosidad respecto del tema [...]" (Kayser, 1964, p. 7). Allí, como continúa, -frente a las criaturas contrahechas y deformes; frente a los enanos de la corte que, sin embargo, trataban de "señor primo" al rey, presentes en los lienzos de Velázquez; frente a Saturno devorando a sus hijos o frente la estampa titulada "Contra el bien general" de los Caprichos con un hombre acurrucado con los dedos terminados en garras y los pies en patas- se le había presentado el mismo fenómeno inquietante y desconcertante que vino a describir en su libro. Lo advirtió también un historiador polaco, Bronisław Geremek quien en su libro dedicado a la novela picaresca europea constataba que si de la suerte de los mendigos y los vagabundos se ocupaba en Europa la literatura popular, en el caso español la descripción de sus experiencias entró en las obras canónicas (Geremek, 1989). Son ejemplos remotos y generales. De los más cercanos y concretos, apuntemos por ejemplo la descripción que de los protagonistas del mundo novelístico de Camilo José Cela, predominantemente los marginados y los minusválidos, hace en su estudio Magda Potok según la cual la esencia del acto literario celiano consiste en una presentación sugestiva de toda anomalía (Potok, 2016). Tal decisión personifica una desesperación para la que no existe ninguna consolación y constituye a largo plazo fruto de un profundo pesimismo o fatalismo del autor.

La deformidad humana de la que estoy hablando y que tantas veces viene representada en las páginas de las novelas españolas del siglo XX y XXI (desde el citado Camilo José Cela, pasando por Juan Marsé y Miguel Delibes y terminado en Juan José Millás y Terenci Moix) equivale mayoritariamente a la discapacidad física o intelectual. Los discapacitados que constituyen aproximadamente el 10\% de la población siempre vivían en una situación de inferioridad dentro de la sociedad -un grupo paria, siguiendo el término de Hannah Arendt (Arendt, 2013)- siendo excluidos de ventajas de las que gozan los demás y carentes de derechos políticos. La frecuencia con la que su imagen se manifiesta en los mundos representados anteriormente citados nos permite preguntar por el lugar que allí ocupa este grupo excluido. Nos incita también a reflexionar desde qué punto de vista y en qué totalidad esta minoría viene representada por los narradores, cómo reaccionan ante ella los demás participantes de la ficción. ¿Los discapacitados aparecen situados entre los demás miembros del mundo heterogéneo de modo que nadie se da cuenta de su "excepcionalidad" o, al contrario, su "anormalidad" viene a formar su única seña de identidad? ¿Se sienten libres e iguales o totalmente solos y aislados? ¿La fealdad provoca en el receptor real la inquietud? ¿Qué lenguaje (diminutivos, aumentativos, elipsis) y qué imaginería se aplica? ¿Cómo se explica la discapacidad y si a la probable imposibilidad de tal explicación acompaña la inexpresabilidad artística? ¿La discapacidad 
está vista cómo la caída social, como la destrucción del orden natural de las cosas o, al revés, se trata de una presentación de los casos particulares?

Entre los ejemplos más recientes de las imágenes de discapacidad en la narrativa española podemos señalar dos obras unidas por el intento de reproducir el pensamiento muy coherente, lógico y moralmente fuerte aunque a veces violento de las personas minusválidas. Se trata primero de la reconocida al unísono novela Patria de Fernando Aramburu editada en 2016 por Tusquets en la que Arantxa, una de las protagonistas, después de sufrir un infarto cerebral, vive en una silla de ruedas, inmóvil e incapaz de hablar. Ella compara su minusvalía a la situación que vive su hermano, miembro del grupo terrorista, condenado a varios años de reclusión. Arantxa le hace consciente de que su pena es más dura por perpetua, irreversible y sin culpa y su discapacidad poco a poco suscita en el prisionero el desengaño, la responsabilidad y finalmente el arrepentimiento. Así la minusvalía de Arantxa se vuelve motor de la compasión de su hermano y, por consiguiente, de su autoconciencia. Se puede equiparar también la parálisis de la protagonista con la enfermedad y la pena de la viuda cuyo marido fue víctima de ETA. Ambas mujeres sufren sin delito alguno, sin embargo el ictus, un accidente sin culpa, ocurrido al azar le deja a Arantxa y, más aún, a su familia sin enemigo, sin responsable, sin alguien a quien se le pueda reclamar perdón. La protagonista discapacitada aunque se siente rota en pedazos, es moralmente más intacta y fuerte, consigue forzar a su hermano a una autoevaluación, ablandar a su madre intransigente, conciliar las dos familias enemistadas. El difícil trabajo de rehabilitación de los músculos de Arantxa transcurre al compás de la recuperación de unas relaciones sociales entre los antiguos amigos.

Otro ejemplo reciente de la voz de los discapacitados en la narrativa se halla en una obra heterogénea y valiente de Cristina Morales titulada Lectura fácil editada por Anagrama a finales de 2018. La novela resultó ganadora del Premio Herralde de Novela y también, dos años después de la anteriormente aludida Patria de Fernando Aramburu, en octubre de 2019, obtuvo el prestigioso Premio Nacional de Narrativa. Aquí, a diferencia de la obra de Aramburu, las cuatro protagonistas -todas con discapacidad intelectual- son personajes centrales y su dicción engloba la totalidad del libro. Cristina Morales es escritora, pero también forma parte de la compañía de danza contemporánea denominada "Iniciativa Sexual Femenina" y, como confiesa en las entrevistas, ha trabajado a través del baile con las personas con discapacidad, sobre todo física, pero a veces también intelectual. "Esa diversidad funcional de lo que antes se llamaba el loco o el tonto del pueblo -ha declarado para El País Cataluña- me parece de una gran potencia, como demostró Los santos inocentes, con su crítica de clase; me interesa esa gran potencia crítica que hay en los márgenes de los márgenes; y confrontar la retórica institucional con la del supuesto analfabeto" (Geli, 2018, párr. 2).

Su novela está compuesta de varios materiales: declaraciones de las protagonistas ante el juzgado, cartas dictadas a Plataforma de Afectados por la Hipoteca, 
actas de las reuniones de la asamblea de un grupo de okupas, novela autobiográfica de una de las protagonistas escrita en la aplicación de mensajería WhatsApp según método de lectura fácil, fragmentos de fanzines leídos por otra, todo ello mezclado con la narración escrita desde la primera persona por una de las chicas. Estamos por lo tanto ante una voz directa y tres voces que nos llegan a través de soportes auxiliares que recrean la oralidad. Precisamente éste es un rasgo destacado por el jurado de Premio Nacional de Narrativa -al lado de la radicalidad y la originalidad del libro- al anunciar el fallo.

Son hermanas y primas entre ellas que provienen de un pueblo ficticio de Arcuelamora a quienes conocemos viviendo en un piso tutelado en Barcelona: Ángeles de 43 años, con el $40 \%$ de la discapacidad y 189 euros de pensión, escribe novela en WhatsApp, mira mucho la tele, ha trabajado en Mercadona, es tartamuda y obesa; Patricia de 33 años, tiene el 52\% de la discapacidad y la pensión ligeramente superior, se maquilla y fuma mucho, lleva gafas, sufre logorrea; Margarita de 37 años, con el $66 \%$ de la discapacidad y 438 euros de pensión, sabe limpiar bien, aunque necesita ayuda a la hora de cortarse las uñas, es analfabeta, ha sufrido depresión después de darse cuenta de su peculiaridad, por su gran actividad sexual ha sido obligada judicialmente a la esterilización; Natividad, también treintañera, del $70 \%$ de discapacidad y 1118 euros de pensión, obesa, va a las clases de baile, estudió en la Universidad Autónoma donde un mes antes de presentar la tesis doctoral tuvo un accidente laboral y ahora sufre, como dice, el "síndrome de las compuertas" que ella compara a las puertas del metro que cierran en vertical, distanciando herméticamente al viajero de la realidad del andén; tal discapacidad la deja separada de la realidad, no le permite admitir ni entender bromas y la obliga, en cambio, a gritar y discutir con palabras repetidas maniáticamente.

Todas ellas son conscientes de su deficiencia y otredad y aceptan su condición. Una de ellas empieza su explicación con las siguientes palabras: „,...] es evidente que yo soy retrasada mental, y [...] es evidente que los retrasados mentales no hablan igual ni de los mismos temas ni les importan las mismas cosas que a los que no son retrasados mentales [...]" (Morales, 2018, pos. 1914). Entienden que viven en una especie de opresión aunque cada una lo manifiesta a su manera. En lo que sí están de acuerdo es que no se les obligue a callar ya que su experiencia de toda la educación en los centros y escuelas para los niños con discapacidad intelectual ha sido precisamente guardarse para sí todo pensamiento o emoción. Las cuatro luchan contra diversas formas de represión. Desean ardientemente una simple libertad para sí: poder sentarse en un banco con vistas al mar, beber una cerveza en el bar, fumarse un cigarrillo en el balcón, disponer de su cuerpo, vivir a solas aunque sea unos pocos días y aunque sea en un piso okupado sin baño y con agujeros en el techo. De forma parecida al recurso de Fernando Aramburu quien, como recordamos, cotejaba la parálisis del cuerpo de Arantxa con la reclusión carcelaria de su hermano y al igual que lo hace una conocida autora estadounidense, Bebe Moore Campbell en su 
novela 72-Hour Hold sobre una chica negra que sufre enfermedad mental, Cristina Morales utiliza muchas veces la metáfora de la esclavitud. Sin embargo, no se trata de la opresión interna como en el caso de la novelista americana, sino de la opresión externa e institucional. Las chicas en los centros o en su piso tutelado y controlado por los representantes de la Generalitat se sienten esclavas o presas. No se les permite fumar, beber cerveza, volver tarde a casa, en cambio están obligadas a mantener el orden y la limpieza en el piso. El sistema les resulta mucho más opresivo y violento que la experiencia de la enfermedad misma.

Las cuatro han ido estableciendo poco a poco la regla de no deprimirse o doblegarse ante los comportamientos normalizadores del sistema, sino, por lo contrario, radicalizarse cuestionando de esta manera la cultura dominante. Quieren que la aversión que suscitan en los representantes de la norma se vuelva miedo o incluso asco. Persiguen diferentes palabras, expresiones, gestos propios del poder que se sirve de la amabilidad falsa o de la infantilización de tipo: “¿entiendes español?”, “¿te importa que...?". Natividad, la más retrasada y al mismo tiempo la más rebelde e intransigente de las cuatro mujeres, quizá por su "síndrome de las compuertas", durante una clase de danza integrada observa el intento de obligar a una artificial fluidez de movimientos a un chico en silla de ruedas, con la columna vertebral torcida, una pierna más larga y la cadera desnivelada. Se está dando cuenta de que la danza integrada significa, al fin y al cabo, no una verdadera libertad de movimientos sino que los cuerpos y las mentes no normalizados se integren en el sistema gobernante de cuerpos y mentes respetuosos con la norma. Su espíritu radical va a proponer, por lo tanto, que se cambie la fluidez de los movimientos por confusión o hasta envilecimiento. Su discurso frente a tal observación es el siguiente:

Eso busca la estilización: la normalización. Eso quiere decir el tridente dancístico de fluidez, seguridad y belleza: normalización. Hasta eso quiere decir superarse: normalizarse, volverse ciudadano, volverse igual. El espíritu de superación, qué sibilinas que son las palabras, es el espíritu de normalización. Deja de ser quién eres para convertirte en un mediocre más. El espíritu de superación es, pues, el espíritu de la mediocridad. ¿Y qué es un mediocre? Mediocre no es un corredor que queda el vigesimoctavo en la clasificación, no. Ese puede ser, simplemente, un mal corredor. Mediocre es el ganador de la carrera que en el podio agradece su victoria al banco o a la petrolera que lo patrocina. Mediocre es lo inofensivo. [...] mediocre es el integrado y por tanto mediocre es la danza integrada. (Morales, 2018, pos. 2470)

Como apunta Jim Ferris, existe la discapacidad, pero existe también el modelo social de la discapacidad, un constructo social cuyas consecuencias sufren los discapacitados (Ferris, 2017). El comportamiento de las protagonistas de Lectura fácil apela a que no se imponga a la otredad interpretaciones o suposiciones falsas y apela también a la igualdad que significa el derecho de toda persona a formar parte del espacio público. 
Las cuatro mujeres discapacitadas resultan al final indomables para el sistema, permanecen totalmente rebeldes contra las reglas institucionales que entienden, pero deciden saltar. Con su conducta demuestran una vez más la verdad de la constatación conocida desde los tiempo del Quijote que la supuesta incapacitación vuelve a los incapacitados más lúcidos $\mathrm{y}$, en cambio, deja en ridículo a los que permanecen dentro de la norma y viven de acuerdo con sus preceptos. Cristina Morales presenta la discapacidad de sus protagonistas como una forma de la diversidad humana, en este caso la diversidad no física sino cognitiva. Al mismo tiempo su novela subvierte la ideología de éxito y del ideal normativo y señala qué significa para las personas no-normativas la obsesión por lo utilitario y lo racional.

Como ya hemos apuntado, las protagonistas son conscientes de sus discapacidades mentales. Hay que añadir además que, al mismo tiempo, aceptan sus cuerpos: hablan abiertamente de sus necesidades fisiológicas y sexuales, de la obesidad y los sudores, de la comodidad de los sostenes y pantalones, de sus apetitos eróticos. ${ }^{1}$ En Lectura fácil lo físico está puesto al descubierto, todo es asquerosamente real y corporal aunque -y es un gran logro de la novelista- no da asco. ${ }^{2}$ Las protagonistas aceptan la inmanencia de su corporeidad, se conforman con la fuerza instintiva de sus deseos lo cual, a su vez, parece constituir un primer paso para mejorar la condición humana y superar las dolientes dicotomías entre pecado y virtud o entre el cuerpo y el alma. Bernard McElroy llamaba la atención sobre el hecho de que la imagen de cuerpo o mente deformadas solían despertar miedos primitivos relacionados con la identidad humana, con la inexplicable influencia ajena y con la posibilidad de que en los mismos procesos naturales funciona alguna regla enemiga (Mcelroy, 2003, p. 138). Cristina Morales con sus valientes protagonistas supera las inquietudes irracionales de los que defienden las fronteras constantes de la identidad, optan por proteger distancias, consolidan diferencias, conservan disonancias y dominan los agudos recelos ante los "extraños".

Cristina Morales ha conseguido encontrar un lenguaje propio para hablar de la discapacidad que se aparta de un lenguaje sociológico que suele reducir al individuo. La escritora tampoco aborda el tema de forma abstracta o alegórica, presenta problemas reales y concretos. Sabe evitar la banalización y la infantilización. Sus protagonistas no son "niñas sociales", objetos de tutela o de exclusión. Morales tampoco

\footnotetext{
${ }^{1}$ Abby L. Wilkerson sostiene que las personas con discapacidades carecen de poder político porque a menudo están desexualizadas y la falta de agencia sexual conduce a la falta de agencia política. Wilkerson también indica que la erotofobia hacia grupos minoritarios como las personas con discapacidades los oprime aún más, ya que impide que estos grupos ganen poder político a través de la agencia sexual. (Wilkerson, 2002)

${ }^{2}$ Vale la pena recordar en este contexto la constatación de Elisabeth Roudinesco que recurriendo a los místicos cuya habla se nutría de anomalías y cuyo cuerpo debía destruirse para poder entrar en el mundo de las cosas fundamentales, reconocía que toda la literatura del asco era una literatura moral ya que el objeto del asco aunque no busque la trascendencia, se vuelve expresión de lo transcendente y lo inexpresable. (Roudinesco, 2009, p. 17)
} 
intenta deslumbrar al lector con las descripciones de las "excepcionalidades" de las chicas. Es un lenguaje carente de una especial ternura, un lenguaje igualitario.

Hay que subrayar que las protagonistas luchan por la libertad de los intentos normalizadores del sistema opresivo, pero su posición entre los demás protagonistas ficticios como los camareros del bar, los colegas del movimiento okupacional, etc. no es problemática. Las cuatro mujeres adultas tratadas por el sistema de forma más severa que menores de edad (oficialmente no pueden comprar cigarrillos ni alcohol), saben arreglarse las facturas falsas con el chino, dueño de la tienda. Consiguen que los camareros pongan en las cuentas "dos bebidas", en vez de "dos cervezas". La gente alrededor no las trata mal, sin ningún ademán de superioridad. Todo lo contrario, la gente apenas parece percibir su otredad. Durante la asamblea del grupo de okupación a consecuencia de una pregunta de Margarita se desarrolla un largo y emocional debate abstracto y teórico entre los participantes que no sólo no se fijan en su discapacidad, pero apenas se dan cuenta cuando la chica tiene que irse. La novela de Morales constituye una intervención en contra de la terapéutica cultura occidental, se declara en contra de curar, mejorar y así ajustar a la norma y esconder lo deforme. Es adversaria de las instituciones rehabilitadoras que siguen el ideal de asemejar a los ciudadanos y de no indicar las diferencias que les separan. Por el contrario, propone la aceptación de la discapacidad y la fealdad. He aquí quizá el mismo pesimismo o fatalismo al que recurría Magda Potok comentando la novelística de Cela. Cristina Morales no tiene la intención de suavizar la realidad, está conforme con que la discapacidad existe lo cual le permite evitar el sentimentalismo. Sabe domesticar la deficiencia, por consiguiente, sus protagonistas normativos apenas perciben la excepcionalidad de las cuatro mujeres de Arcuelamora. Harlan Hahn, investigador relacionado con la disciplina conocida como Disability Studies, distingue dos tipos de inquietud social hacia los discapacitados: la inquietud existencial relativa a la pregunta cómo la discapacidad amenaza mi visión de la vida funcional y la inquietud estética relativa a la pregunta cómo la discapacidad amenaza a mi visión de cuerpo o mente ideal (Hahn, 1988, pp. 42-43). Estas inquietudes apenas parecen turbar a los personajes de las ficciones españolas.

$\mathrm{Al}$ barajar varias hipótesis, la que más me convence por ahora es que las descripciones españolas de la discapacidad carecen de la perspectiva de superioridad, pero también de una perspectiva emocional distinta y diferente en comparación con los retratos de los personajes normativos. La representación de la discapacidad queda envuelta en la misma atmósfera que acompaña a los personajes estándar. Volviendo a Velázquez al que recurría Kayser en su prólogo citado, él pinta con la misma majestuosidad y la misma solemnidad los retratos de las infantas y de los enanos. Buñuel retrata con la misma ironía a los burgueses en Discreto encanto a la burguesía y a los mendigos, ciegos, retrasados de Viridiana. Delibes con la misma ternura describe a Daniel de El camino y a Azarías de Los santos inocentes. Es decir: los mismos recursos estilísticos se aplican -utilizando la oposición de Hannah 
Arendt- tanto a los parias, como a los advendizos. Muchas veces la especificidad de la presentación de la discapacidad es resultado de crear un visible aislamiento intelectual por parte del sujeto hablante. En tales casos (de ejemplo puede servir el teatro valleinclanesco) se subvierte la autenticidad de la realidad descrita que se vuelve desmesurada y absurda. Muchas veces también, y éste es el caso de Cristina Morales, la especificidad de la presentación de la discapacidad es resultado de marcar una clara distancia emocional al mundo representado por parte del narrador, aquí reforzada por los materiales heterogéneos que componen la novela y detrás de los que éste se oculta. La imagen de la discapacidad pocas veces tiene el objetivo de conmover al lector a través de una retórica sentimental o de despertar su admiración a través de la definida por R. Garland-Thomson retórica de lo maravilloso o de sorprenderle a través de la retórica de exotismo (Garland-Thomson, 2002). En la obra de Cristina Morales no es posible para nada aplicar la categoría de la "prótesis narrativa" introducida por David T. Mitchell y Sharon L. Snyder para los autores quienes presentan la discapacidad como una situación particular y crítica y un juego de rasgos estereotipados que recurren a los conceptos centrados en la limitación corporal a diferencia del cuerpo sano que siempre es transparente. Allí la prótesis sustituye los elementos necesarios tales como la justificación de actitudes o la representación verosímil de la realidad. Aquí, en la obra de Morales, no se da tal discapacidad del texto.

Cabe preguntar por las causas de la persistencia de la estética de fealdad que viene a constituir una herramienta importante de la expresión artística. Aquí se desarrolla todo un abanico de posibilidades. Theodor W. Adorno caminando en sentido contrario que la mayoría de los filósofos que primero definen la belleza y luego describen la fealdad como su falta, llega a la conclusión de que la belleza se ha desarrollado rechazando lo que provocaba anteriormente el miedo (Adorno, 1994). Así une la fealdad con el miedo lo cual nos hace entender el esfuerzo de Cristina Morales como un intento de exorcizar los temores, un intento de ocasionar que lo que provoca sustos deje de horrorizar a los lectores. Otra posible explicación más histórica que filosófica alude al barroco español como un momento decisivo para el desarrollo de la especificidad y la idiosincrasia de la cultura española. Roberto González Echevarría señala en su libro La prole de Celestina. Continuidades del barroco en las literaturas española e hispanoamericana que el concepto de "yo" típico para el barroco se caracteriza por la aceptación del otro a modo de la conciencia de la extrañeza de la existencia humana.

El barroco asume la extrañeza del Otro como conciencia de la extrañeza del ser. El ser que es ser monstruo, una combinación de Yo y el Otro, simultáneamente uno y el mismo, igual y diferente. [...] Esto es lo que se pone en juego en el arte barroco: la conciencia de la otredad en el seno del propio ser, de la novedad y rareza del ser. (González Echevarría, 1999, p. 231) 
La sensación de ser como diferencia es en el barroco concreta y tangible. "Es la sensación de la propia rareza, de la propia extrañeza, de la propia deformación" (González Echevarría, 1999, p. 231). Es por lo tanto Cristina Morales heredera del barroco, del barroco que "no es un arete idealista, sino un arte apegado a la burda y torpe materialidad del mundo, con sus contrastes y contradicciones" (González Echevarría, 1999, p. 144). 


\section{BIBLIOGRAFÍA}

Adorno, Th.W. (1994). Teoria estetyczna (trad. K. Krzemieniowa). Warszawa: PWN (Original work published 1970).

Aramburu, F. (2016). Patria. Barcelona: Tusquets.

Arendt, H. (2013). Rahel Varnhagen. Historia życia niemieckiej Żydówki z epoki romantyzmu (trad. K. Leszczyńska). Sejny: Pogranicze (Original work published 1957).

Campbell, M.B. (2005). 72 hour hold. New York: Knopf.

Ferris, J. (2017). Dystans estetyczny i fikcja niepełnosprawności. En E. Godlewska-Byliniak, J. Lipko-Konieczna (eds.), Odzyskiwanie obecności. Niepetnosprawność w teatrze i performansie (127-142). Warszawa: Fundacja Teatr 21.

Garland-Thomson, R. (2002). The Politics of Straring: Visual Rhetorics of Disability in Popular Photography. En S.L. Snyder, B.J. Brueggemann, R. Garland-Thomson (eds.), Disability Studies. Entabling the Humanities (56-75). New York: The Modern Language Assotiation of America.

Geli, C. (2018, noviembre 5). Cristina Morales gana el Herralde con una novela de combate. El País Cataluña. Recuperado de https://elpais.com.

Geremek, B. (1989). Świat „opery żebraczej”. Obraz włóczęgów i nędzarzy w literaturach europejskich XV-XVII wieku. Warszawa: Państwowy Instytut Wydawniczy.

González Echevarría, R. (1999). La prole de Celestina. Continuidades del barroco en las literaturas española e hispanoamericana. Madrid: Editorial Colibrí.

Hahn, H. (1988). The Politics of Phisical Difference: Disability and Discrimination. Journal of Social Issues, 44 (1), 39-47.

Kayser, W. (1964). Lo grotesco. Su configuración en pintura y literatura (trad. I.M. de Brugger). Buenos Aires: Editorial Nova (Original work published 1957).

Mcelroy, B. (2003). Groteska i jej współczesna odmiana (trad. M.B. Fedewicz). En M. Głowiński (ed.), Groteska (125-167). Gdańsk: słowo/obraz terytoria.

Mitchell, D.T., Snyder, S.L. (2000). Narrative Prosthesis. Disability and the Dependencies of Discourse. Ann Arbor: University of Michigan Press.

Morales, C. (2018). Lectura fácil. Barcelona: Anagrama (e-book, edición en formato digital, mobi).

Potok, M. (2016). Współczesna proza hiszpańska. Studia. Poznań: Wydawnictwo Naukowe UAM.

Roudinesco, E. (2009). Nasza mroczna strona. Z dziejów perwersji (trad. B. Baran). Warszawa: Czytelnik, PWN (Original work published 2007).

Wilkerson, A. (2002). Disability, Sex Radicalism, and Political Agency. NWSA Journal, 14 (3), 33-57. 